\title{
Protein profiling of ovarian cancers by immunohistochemistry to identify potential target pathways
}

\author{
Cassandra D Foss ${ }^{1,2}$, Heather J Dalton ${ }^{3}$, Bradley J Monk ${ }^{1,2}$, Dana M Chase ${ }^{1,2}$ and John H Farley ${ }^{\text {* }^{*}}$
}

\begin{abstract}
Background: To determine the protein expression profile (PEP) of primary and recurrent ovarian cancer patients in order to predict therapeutic targets for chemotherapy.

Methods: Tissue samples were submitted for PEP in two formats, including formalin-fixed paraffin-embedded tissue for immunohistochemistry (IHC) and fresh frozen tissue for oligonucleotide microarray (MA) gene expression assays. Specimens were analyzed for 18 protein markers and 88 MA genes. A series of Generalized Linear Models (GLM) was used to predict the proportion of positive results by histology for each biomarker.

Results: Four hundred and twenty-eight specimens were analyzed for IHC and 67 specimens for MA analysis. The majority of specimens, $82 \%$, were serous histology and $35.3 \%$ of specimens were poorly differentiated. Sixty percent of specimens were advanced stage, $62 \%$ were from a primary diagnosis, and $53 \%$ were obtained from a metastatic site. BCRP, ER, MGMT, and RRM1 proteins were overexpressed in $85 \%, 47 \%, 93 \%$, and $47 \%$ of serous carcinomas, respectively. The MGMT and RRM1 biomarkers were significantly overexpressed in serous $(p<.001)$ and endometrioid $(p=.01)$ histologies when compared to clear cell histology. MGMT was significantly elevated in $93 \%$ of serous and endometrioid samples, compared to $62 \%$ of samples with clear cell histology. Those proteins most often underexpressed included Her2/neu, SPARC, and c-kit, seen in less than 1\%, 4\%, and 5\% of specimens, respectively.

Conclusions: PEP is a reliable and effective way of analyzing ovarian cancer specimens. PEP target identification does not appear to vary significantly with site evaluated, ovarian or other abdominal pelvic tissue, or primary versus recurrent disease. Variability in the expression of drug targets, including BCRP, ER, MGMT, and RRM1 could impact decision making pertaining to which therapeutic strategies carry the best chances for controlling disease.
\end{abstract}

Keywords: Protein profiling, Ovarian cancer, Immunohistochemistry

\section{Background}

Ovarian cancer is the fifth-leading cause of cancer death among women in the United States [1]. The current standard initial treatment of epithelial ovarian cancer includes surgical staging with optimal tumor debulking, followed by the administration of six cycles of intravenous chemotherapy with carboplatin and placlitaxel [2]. Although more than $80 \%$ of patients benefit from first-line therapy, tumor recurrence develops in nearly all patients, at a median of 15 months from completion of treatment

\footnotetext{
*Correspondence: john.farley@chw.edu

'Division of Gynecologic Oncology, Department of Obstetrics and Gynecology, University of Arizona Cancer Center, 500 W. Thomas Road, Suite 600, Phoenix, AZ 85013, USA

Full list of author information is available at the end of the article
}

[2]. Moreover, platinum resistance occurs in $25 \%$ of patients within 6 months from the last administration of platinum-agent [3], and the overall five-year survival rate of advanced stage disease is $37 \%$ [1]. For this reason, ovarian cancer is considered a systemic disease, and systemic therapies are being increasingly relied upon for treatment.

In the recurrent setting, tumor molecular profiling has been an area of recent investigation in an attempt to improve patient outcomes by employing targeted chemotherapeutic agents. In a pilot study, Von Hoff et al. [4] performed molecular profiling (MP) in 86 patients with refractory metastatic cancers. Of the $27 \%$ of patients who received targeted chemotherapy, the MP approach resulted in a longer progression-free survival than the 
regimen on which the patient had just experienced progression.

In another study, The Cancer Genome Atlas (TCGA) researchers reported DNA gene mutations on tumor samples in patients with high-grade serous ovarian carcinomas (HGS-OvCa) [3]. Their findings were significant for TP53 mutations being identified in nearly all tumors (96\%), while BRCA1 and BRCA2 mutations were identified in $22 \%$ of tumors. Their results indicated that the mutational spectrum of HGS-OvCa is distinct from other histological subtypes of ovarian cancer. Further study would therefore warrant the investigation of targeted therapies based on the specific molecular alterations identified in a specific histology of ovarian cancer.

To date, there is modest data regarding MP of ovarian cancer specimens. Of the 86 patients in the Von Hoff study, only 5 had ovarian cancer [4]. Furthermore, the TCGA data was limited to specimens with high-grade serous histology. The objective of the current study, therefore, is to determine the protein expression profile of primary and recurrent ovarian cancer patients of all histological types in order to predict potential therapeutic targets for chemotherapy.

\section{Methods}

The Target Now $^{\circ}$ (Caris Life Sciences ${ }^{\circ}$ ) database was accessed to obtain MP results for ovarian cancer tissue samples. De-identified results of Target $\mathrm{Now}^{\circ}$, as well as available histopathologic and clinical data from the Caris Life Sciences ${ }^{10}$ database were obtained after Institutional Review Board (IRB) approval. Because the research involved data collected previously for clinical utility (non-research purposes), this study qualified and was approved for expedited review by the IRB at St. Joseph's Hospital and Medical Center. Data was transferred from Caris Life Sciences ${ }^{\oplus}$ to the investigators in the form of a limited data set in compliance with a Data Transfer Agreement.

\section{Immunohistochemistry}

The database was used to analyze formalin fixed tissue samples for protein expression profile (PEP) by immunohistochemistry (IHC), which were obtained from women with primary and recurrent ovarian carcinoma, $62 \%$ and $37 \%$ respectively. Specimens were collected between January 2010 and December 2010. A total of 428 specimens were analyzed for 18 protein markers specific to the Target Now ${ }^{\circ}$ PEP: Androgen Receptor, BCRP, c-kit, ER/PR, ERCC1, Her2/Neu, MGMT, MRP1, PDGFR, PGP, PTEN, RRM1, SPARC, TOP2A, TOPO1, TS, CMET, TUBB3. Analyses were performed by Caris Life Sciences ${ }^{\circ}$ (Irving, Tx). The tests performed by Caris Life Sciences ${ }^{\circ}$ were part of the Target Now MP service. Staining protocols employed the Ventana Medical Systems, Inc. (Tucson, AZ) automated staining systems. Following heat-induced epitope retrieval, antibody incubation was for 20-40 minutes (antibody-specific), and visualization procedure was based on the staining system. Appropriate positive and negative control specimens and slides were included for all of the proteins tested. Slides were evaluated semi-quantitatively for staining intensity on a scale of 0 (no staining) to 3 and by the percentage of the tumor cells showing the reactivity. For IHC scoring appropriate positive and negative thresholds were defined and considered in the subsequent statistical analyses with intermediate and unknown results considered not evaluable. Comparison of IHC results with clinical variables was performed with Fisher's exact test.

\section{Oligonucleotide microarray (MA) gene expression}

A total of $67(25 \%)$ of the 264 primary specimens were analyzed for MA. Normal tissue from the abdominal pelvic cavity was used as a control organ. No specific site was ever designated as a control, the only requirement being that it was uninvolved with cancer. The arrays contain probes for 88 genes for which there is a therapeutic agent that could potentially interact with that gene. Those 88 genes are listed in Additional file 1: Table S1. The frozen tumor fragments for MA were placed in a glass tube on $0.5 \mathrm{~mL}$ of frozen $0.5 \mathrm{M}$ guanidine isothiocyanate solution, thawed, and homogenized with a Covaris S2 (Covari, Woburn, MA). RNA was bound and then eluted. RNA was tested for integrity by assessing the ratio of $28 \mathrm{~S}$ to $18 \mathrm{~S}$ ribosomal RNA on an Agilent BioAnalyzer (Agilent, Santa Clara, CA). Tumor RNA (2 to $5 \mu \mathrm{g}$ ) and control RNA from a sample of a normal tissue representative of the tumor's tissue of origin $(2$ to $5 \mu \mathrm{g})$ were converted to cDNA and labeled during T7 polymerase amplification with contrasting fluor tagged (Cy3, Cy5) cytidine triphosphate. The labeled tumor and its tissue of origin reference were hybridized to an Agilent H1Av2 60-mer oligo array chip with 17,085 unique probes. The chips were then scanned on an Agilent Microarray Scanner (Agilent, Santa Clara, CA). Fluorescence intensity data were extracted, normalized, and analyzed using Agilent Feature Extraction Software. The MA was considered positive for a target if the difference in expression for a gene between tumor and control organ tissue was at a significance level of $P \leq .001$. Cut points were chosen for gene expression of the cancer based on stringent $P$ values $(P<.001)$ compared with the normal mRNA expression levels. It was decided that using the mRNA level from the tissue of the organ of tumor origin would be the most informative comparison. To provide stringent quality control, these MA studies were performed in a Clinical Laboratory Improvement Amendments-certified environment.

\section{Statistical analysis}

Generalized Linear Models (GLM) were used with binomial distribution and link logit specified to predict the 
dichotomous outcome variable overexpression from the categorical predictor histology. Histologies classified as other was set as the reference group for the computation of parameter estimate odds ratios. One GLM model per biomarker was conducted resulting in eighteen models. The False Discovery Rate ${ }^{\text {(SITE) }}$ correction used to adjust for multiple comparisons for significant GLM models. SPSS version 20 was used for statistical analyses.

\section{Results}

Specimens were obtained from 428 females with a median age of 62 years (Table 1). The majority of specimens analyzed by IHC were of serous and carcinoma histology (82\%, Table 2). Thirty-five percent of specimens were poorly differentiated, while $27 \%$ were of unknown histological grade. Of the primary specimens, $62 \%$ were from adnexa, while $53 \%$ were obtained from a metastatic site and not the adnexa. Of the 67 specimens analyzed by MA, $55(82 \%)$ were serous histology, 4 (6\%) endometrioid, 2 (3\%) clear cell, and $6(9 \%)$ other. An advanced-stage diagnosis was represented in $60 \%$ of specimens. Five of the eighteen binomial GLM models predicting protein overexpression were significant. Significant models were for BCRP, ER, MGMT, RRM1, and PTEN at the trend level

Table 1 Patient characteristics at diagnosis

\begin{tabular}{lll}
\hline & (N) & Percent $\%$ \\
\hline TOTAL & 428 & \\
Median age (years) & 61.7 & \\
Tumor histology & & 82 \\
$\quad$ Serous & 351 & 5 \\
$\quad$ Clear cell & 21 & 7 \\
$\quad$ Endometrioid & 28 & 6 \\
Other & 28 & \\
Tumor stage & & 8 \\
$\quad$ I & 36 & 6 \\
II & 24 & 52 \\
III & 224 & 8 \\
IV & 34 & 26 \\
$\quad$ Missing & 110 & \\
Tumor grade & & 27 \\
Well differentiated & 117 & 10 \\
Moderately differentiated & 43 & 35 \\
Poorly differentiated & 151 & 28 \\
Unknown & 117 & \\
Timing & & \\
Primary & 264 & \\
Recurrent & 157 & \\
\hline
\end{tabular}

(Table 3). Twelve pairwise post hoc comparisons were performed for each significant model resulting in sixty post hoc contrasts (Table 4).

ER protein was significantly overexpressed in $47 \%$ of serous and $50 \%$ of endometrioid samples, while only elevated in only $14 \%$ of clear cell samples. Post-hoc testing demonstrated the ER protein was significantly overexpressed in serous $(\mathrm{p}<.001)$ and endometrioid $(\mathrm{p}=.003)$ histologies when compared to clear cell histology (Table 2). The MGMT and RRM1 biomarkers were also significantly overexpressed in serous $(\mathrm{p}<.001)$ and endometrioid $(\mathrm{p}=.01)$ histologies when compared to clear cell histology. MGMT was significantly elevated in $93 \%$ of serous and endometrioid samples, compared to $62 \%$ of samples with clear cell histology. Only $14 \%$ of clear cell samples were found to have overexpression of RRM1, compared to $47 \%$ of serous and $25 \%$ of endometrioid samples. Those proteins most often underexpressed included Her2/neu, SPARC, and c-kit, seen in less than $1 \%, 4 \%$, and $5 \%$ of specimens, respectively. None of the post hoc comparisons for histology were significant for biomarkers BCRP and PTEN with the FDR correction applied.

There were 88 genes evaluated by MA gene expression and included in statistical analysis for association with histology. Those genes most overexpressed, defined as a difference in expression of mRNA between tumor and control organ tissue at a significance level of $P \leq .001$, in serous histology included TOP2A, MSH2, OGFR, RRM2, GART, and PARP1. A description of proportion of positive expression is shown in Figure 1. There were fourteen genes that were never expressed in serous histology and are not shown in Figure 1: ABCG2, AR, CES2, KIT, MS4A1, PDGFRA, PDGFRB, POLA1, RXRB, SPARC, SSTR1, SSTR2, SSTR4, and TOP1. There was no difference in protein or gene overexpression identified when analyzed by age, FIGO stage, grade, primary or recurrent tumor, and ovary or other biopsy site.

\section{Discussion}

TCGA project has analyzed post-transcriptional messenger RNA expression, microRNA expression, promoter methylation, and DNA copy number in 489 high-grade serous ovarian adenocarcinomas [3]. They reported that highgrade serous ovarian cancer is characterized by TP53 mutations in almost all tumors (96\%); and a low prevalence but statistically significant recurrent somatic mutations in nine further genes including NF1, BRCA1, BRCA2, RB1, and CDK12. Pathway analyses suggested that homologous recombination was a potentially important pathway and was defective in about half of the high grade serous cancers analyzed. $\mathrm{NOTCH}$ and FOXM1 signaling were involved in serous ovarian cancer pathophysiology.

Molecular PEP is a powerful approach to identify clinical markers for diagnosis and prognosis as in epithelial ovarian 
Table 2 Counts and proportions of overexpression for biomarkers by histology

\begin{tabular}{lllll}
\hline Biomarker & Serous mean (sd) & Clear cell mean (sd) & Endometrioid mean (sd) & Other mean (sd) \\
\hline 1 Androgen receptor & $.27(.44)$ & $.10(.31)$ & $.27(.45)$ & $.12(.33)$ \\
2 BCRP* & $.85(.36)$ & $.85(.37)$ & $.65(.49)$ & $.72(.46)$ \\
3 C-kit & $.05(.22)$ & $.00(.00)$ & $.00(.00)$ & $.00(.00)$ \\
4 ER* & $.47(.50)$ & $.14(.36)$ & $.50(.51)$ & $.39(.50)$ \\
5 ERCC1 & $.24(.43)$ & $.33(.48)$ & $.04(.19)$ & $.25(.44)$ \\
6 Her2/Neu & $.01(.09)$ & $.00(.00)$ & $.00(.00)$ & $.00(.00)$ \\
7 MGMT*** & $.93(.25)$ & $.62(.50)$ & $.93(.26)$ & $.89(.32)$ \\
8 MRP1 & $.89(.32)$ & $.85(.37)$ & $.92(.27)$ & $.92(.27)$ \\
9 PDGFR & $.15(.37)$ & $.23(.43)$ & $.16(.37)$ \\
10 PGP & $.19(.39)$ & $.24(.47)$ & $.21(.42)$ & $.14(.36)$ \\
11 PR & $.39(.49)$ & $.19(.40)$ & $.50(.51)$ & $.36(.49)$ \\
12 PTEN & $.65(.48)$ & $.48(.51)$ & $.43(.50)$ & $.61(.50)$ \\
13 RRM1 ${ }^{* *}$ & $.47(.50)$ & $.14(.36)$ & $.24(.44)$ & $.57(.50)$ \\
14 SPARC MONO & $.11(.32)$ & $.24(.47)$ & $.10(.30)$ & $.16(.37)$ \\
15 SPARC POLY & $.04(.20)$ & $.00(.00)$ & $.00(.00)$ & $.00(.00)$ \\
16 TOP2A & $.39(.49)$ & $.20(.41)$ & $.23(.43)$ & $.40(.50)$ \\
17 TOPO1 & $.89(.32)$ & $.86(.36)$ & $.89(.32)$ & $.93(.26)$ \\
18 TS & $.15(.35)$ & $.05(.22)$ & $.08(.27)$ & $.16(.37)$ \\
\hline P & & &
\end{tabular}

${ }^{* \mathrm{P}}<.05,{ }^{* * \mathrm{P}}<.01,{ }^{* * * \mathrm{P}}<.001$.

cancer. In a previous smaller study, a tissue array composed of 244 serous tumors of different grades (0-3) and stages (I-IV) was evaluated by comprehensive IHC for proteins not necessarily associated with response to selective chemotherapeutic agents [5]. Ccne1, Ran, Cdc20, and Cks1 showed significant differences of expression in association with the clinical stage of disease. The application of these biomarkers in both the initial diagnosis and prognostic attributes of patients with epithelial ovarian tumors could prove to be useful in patient management.

The main objective of this study was to characterize and identify the characteristics of epithelial ovarian cancers through PEP of ovarian tumors in order to predict targeted therapies. The current study is one of the largest PEP

Table 3 Parameter estimates predicting overexpression from histology

\begin{tabular}{|c|c|c|c|c|c|}
\hline & & OR & $95 \% \mathrm{Cl}$ & $P$ & Wald chi-square \\
\hline \multirow[t]{3}{*}{ BCRP } & Carcinoma and serous & 2.21 & $.88-5.58$ & 0.09 & $8.39, p=.039$ \\
\hline & Clear cell & 2.2 & $.49-9.94$ & 0.3 & \\
\hline & Endometriod & 0.735 & $.22-2.41$ & 0.61 & \\
\hline \multirow[t]{3}{*}{ ER } & Carcinoma and serous & 1.39 & $.63-3.05$ & 0.42 & $7.76, p=.051$ \\
\hline & Clear Cell & 0.26 & $.06-1.09$ & 0.07 & \\
\hline & Endometriod & 1.55 & $.54-4.46$ & 0.42 & \\
\hline \multirow[t]{3}{*}{ MGMT } & Carcinoma and serous & 1.64 & $.46-5.81$ & 0.48 & $18.57, p<.001$ \\
\hline & Clear cell & 0.2 & $.04-.86$ & 0.03 & \\
\hline & Endometriod & 1.56 & $.24-10.14$ & 0.64 & \\
\hline \multirow[t]{3}{*}{ PTEN } & Carcinoma and serous & 1.19 & $.54-2.61$ & 0.67 & $7.01, p=.071$ \\
\hline & Clear cell & 0.59 & $.19-1.85$ & 0.36 & \\
\hline & Endometriod & 0.49 & $.17-1.41$ & 0.18 & \\
\hline \multirow[t]{3}{*}{ RRM1 } & Carcinoma and serous & 0.67 & $.31-1.46$ & 0.32 & $13.06, p=.005$ \\
\hline & Clear cell & 0.13 & $.03-.52$ & 0.004 & \\
\hline & Endometriod & 0.25 & $.08-.78$ & 0.017 & \\
\hline
\end{tabular}


Table 4 Post hoc comparisons for significant glm models predicting overexpression

\begin{tabular}{|c|c|c|c|c|c|c|c|c|c|c|c|}
\hline & & \multicolumn{5}{|l|}{ BCRP } & \multicolumn{5}{|l|}{ ER } \\
\hline & & Mean diff & SE & $95 \% \mathrm{LCL}$ & $95 \%$ UCL & $p$ & Mean diff & SE & $95 \% \mathrm{LCL}$ & $95 \%$ UCL & $\mathbf{p}$ \\
\hline Carcinoma and serous & Clear cell & 0 & 0.08 & -0.16 & 0.16 & .993 & 0.33 & 0.08 & 0.17 & 0.49 & $.000^{*}$ \\
\hline Carcinoma and serous & Endometriod & 0.2 & 0.10 & 0.01 & 0.38 & .039 & -0.03 & 0.10 & -0.22 & 0.17 & .783 \\
\hline Carcinoma and serous & Other & 0.13 & 0.09 & -0.05 & 0.31 & .155 & 0.08 & 0.10 & -0.11 & 0.27 & .405 \\
\hline Clear cell & Endometriod & 0.2 & 0.12 & -0.04 & 0.44 & .110 & -0.36 & 0.12 & -0.60 & -0.12 & $.003^{*}$ \\
\hline Clear cell & Other & 0.13 & 0.12 & -0.11 & 0.37 & .279 & -0.25 & 0.12 & -0.48 & -0.02 & .037 \\
\hline \multirow[t]{3}{*}{ Endometriod } & Other & -0.07 & 0.13 & -0.32 & 0.19 & .609 & 0.11 & 0.13 & -0.15 & 0.37 & .417 \\
\hline & & \multicolumn{5}{|l|}{ MGMT } & \multicolumn{5}{|l|}{ RRM1 } \\
\hline & & Mean diff & SE & $95 \% \mathrm{LCL}$ & $95 \%$ UCL & $p$ & Mean diff & SE & 95\% LCL & $95 \%$ UCL & $p$ \\
\hline Carcinoma and serous & Clear cell & 0.31 & 0.11 & 0.10 & 0.52 & $0.00^{*}$ & 0.33 & .081 & .17 & .49 & $.000^{*}$ \\
\hline Carcinoma and serous & Endometriod & 0.00 & 0.05 & -0.10 & 0.10 & 0.95 & 0.22 & .086 & .05 & .39 & $.010^{*}$ \\
\hline Carcinoma and serous & Other & 0.04 & 0.06 & -0.08 & 0.16 & 0.52 & -.10 & .097 & -.29 & .09 & .311 \\
\hline Clear cell & Endometriod & -0.31 & 0.12 & -0.54 & -0.08 & $0.00^{*}$ & -.11 & .112 & -.33 & .11 & .338 \\
\hline Clear cell & Other & -0.27 & 0.12 & -0.51 & -0.04 & 0.02 & -0.43 & .121 & -.67 & -.19 & $.000^{*}$ \\
\hline \multirow[t]{3}{*}{ Endometriod } & Other & 0.04 & 0.08 & -0.11 & 0.18 & 0.95 & -0.32 & .124 & -.56 & -.08 & $.010^{*}$ \\
\hline & & \multicolumn{5}{|l|}{ PTEN } & & & & & \\
\hline & & Mean diff & SE & $95 \%$ LCL & $95 \%$ UCL & $\mathrm{p}$ & & & & & \\
\hline Carcinoma and serous & Clear cell & .17 & .112 & -.05 & .39 & .128 & & & & & \\
\hline Carcinoma and serous & Endometriod & 0.22 & .097 & .03 & .41 & .024 & & & & & \\
\hline Carcinoma and serous & Other & .04 & .096 & -.15 & .23 & .679 & & & & & \\
\hline Clear cell & Endometriod & .05 & .144 & -.23 & .33 & .740 & & & & & \\
\hline Clear cell & Other & -.13 & .143 & -.41 & .15 & .359 & & & & & \\
\hline Endometriod & Other & -.18 & .131 & -.44 & .08 & .174 & & & & & \\
\hline
\end{tabular}




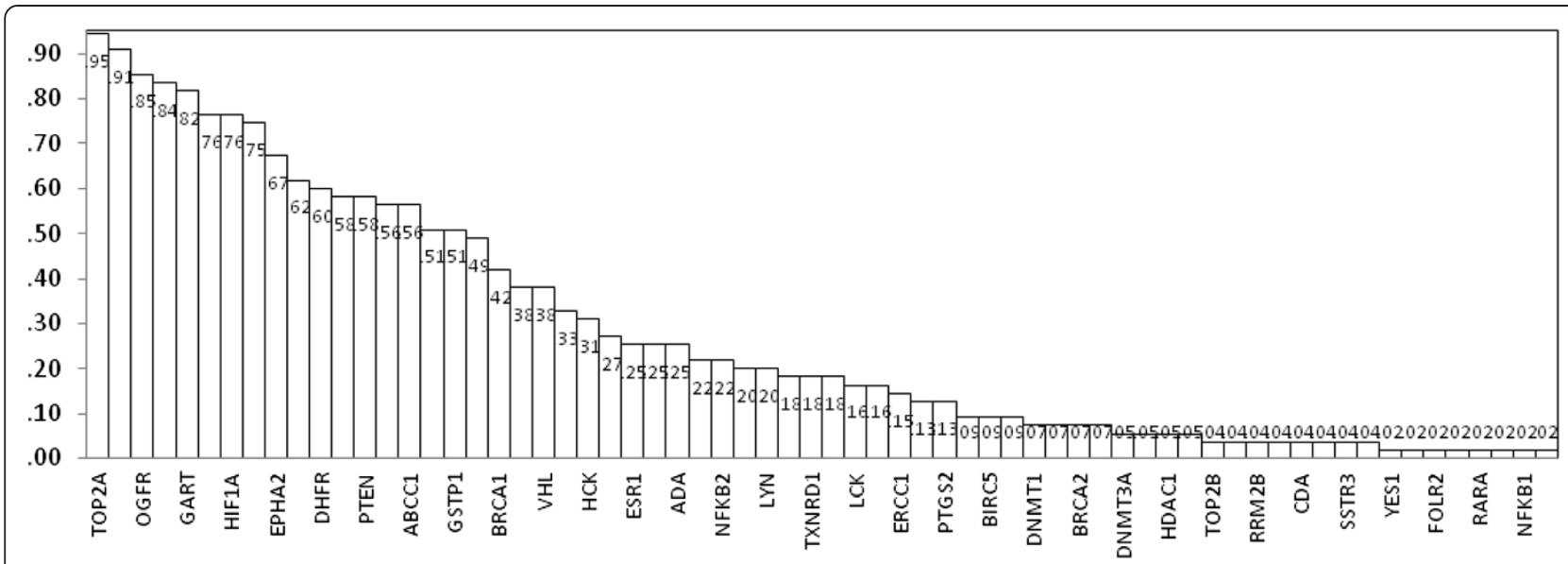

Figure 1 Proportion of protein overexpression by gene for serous ovarian cancer. The figure reports the fraction of serous ovarian cancer samples with overexpressed mRNA by gene. There was no differential expression of genes with regard to stage, grade, or race.

analyses of epithelial ovarian cancers in the literature. This study demonstrates that PEP is a reliable and effective way of analyzing ovarian cancer specimens. In this study, protein expression target identification did not appear to vary significantly with the site evaluated, ovarian or other abdominal pelvic tissue, or with primary versus recurrent disease.

Several markers have been identified which may predict a specific tumor's response to chemotherapy (Table 3). Breast cancer resistance protein (BCRP), an atypical drug efflux pump, mediates multidrug resistance in breast cancer, as well as other cancer types, by reducing the intracellular concentration of cytotoxic drugs [6]. BCRP has been described in breast, colon, gastric cancer, and fibrosarcoma cell lines but has also had documented overexpression in ovarian cancer cell lines [7]. Studies in topotecan-resistant ovarian cancer cell lines have demonstrated a substantial overexpression of BCRP. Moreover, these cell lines demonstrated resistance to other topoisomerase I inhibitors, SN-38 (the active metabolite of irinotecan, and 9-aminocamptothecin, as well as the topoisomerase II inhibitor, mitoxantrone [6,7]). Topotecan, etoposide, mitoxantrone, 5-FU, anthracyclines such as doxorubicin and pirarubicin, as well as methotrexate have all been identified as substrates of BCRP $[8,9]$, and therefore would be less effective in tumors that overexpress this protein. However, paclitaxel, vincristine, vindesine, mitomycin $\mathrm{c}$, and cisplatin are not mediated by BCRP [9] and would likely be more successful in treating patients with tumors that overexpress BCRP.

Tumors which overexpress estrogen receptor (ER) may have an enhanced response to anti-estrogens such as megestrol, tamoxifen, and aromatase inhibitors. These therapies have been used extensively in the treatment of ER-positive breast cancer. However, there is sparse data on ER-positivity in ovarian tumors. In the 'MALOVA' Ovarian Cancer Study, the investigators identified that ER was expressed in $36 \%$ of epithelial ovarian tumors [10]. The authors suggested ER is a prognostic indicator of improved survival in ovarian cancer patients, though no targeted therapy was used in this study. Data on the use of anti-estrogens in the treatment of ovarian cancer is limited to phase II trials with results indicating these therapies, if successful, are predominantly able to achieve disease stabilization, with only marginal rates of partial or complete treatment responses [11-15].

MGMT, or O6-methlyguanine-DNA methyltransferase, is an enzyme that repairs methylated DNA and plays a crucial role in the protection against alkylating agents $[16,17]$. MGMT expression in cancer cells can inhibit the success of chemotherapy treatment with alkylating agents, which work by triggering DNA methylation [18]. If MGMT is overexpressed in the tumor, alkylating agents such as temozolomide may be less effective. Low expression of MGMT has been associated with successful response to treatment with temozolomide [19]. Furthermore, inhibition of MGMT activity has been shown to increase the toxicity of alkylating agents $[17,18]$.

RRM1 is a subunit of Ribonucleotide reductase (RR), an enzyme that acts as the rate-limiting step in DNA synthesis, as it is the only known enzyme to convert ribonucleotides to deoxyribonucleotides for DNA polymerization and repair. It functions with the p53-regulated RRM2 homologue p53R2 and is important in DNA repair secondary to genotoxic stress [20]. Gemcitabine is an analog of deoxycytidine and is converted intracellularly into active diphosphate and triphosphate nucleosides, which become incorporated into the DNA chain, leading to termination of chain elongation and inhibition of DNA synthesis [21]. In preclinical studies, increased RRM1 
expression and activity have been shown to be markers for gemcitabine resistance, suggesting that RRM1 expression is a negative predictor of gemcitabine efficacy [20-24]. However, patients with low as compared to high levels of tumoral RRM1 expression had improved survival when treated with gemcitabine-based therapy [25].

In this particular study, BCRP, ER, MGMT, and RRM1 proteins were overexpressed in $85 \%, 47 \%, 93 \%$, and $47 \%$ of serous carcinomas, respectively. As these proteins have been shown to be associated with various resistances to specific chemotherapeutic agents, targeted therapy may be helpful in identifying successful treatments. Because of the increased expression of BCRP, MGMT, and RRM1 identified in serous carcinomas, in theory chemotherapeutic agents such as etoposide, adriamycin, temozolomide, and gemcitabine may be avoided in the treatment of serous tumors that overexpress these biomarkers and considered only for other histologies of ovarian cancer.

On the other hand, for a segment of the ovarian cancer population, drugs that have not been developed in ovarian cancer, such as temozolomide, could be useful for patients with the right biomarker profile, such as low MGMT expression, perhaps even in preference to giving a standard drug like topotecan to a patient with suboptimal biomarker expression, such as low TOPO1. In this way, PEP offers a laboratory-based approach to drug selection, rather than the empiric method of selecting drugs blindly. Accordingly, PEP could impact medical decision-making by prioritizing which standard agents are most likely and least likely to offer benefit to the individual patient, as well as identifying drugs outside the standard armamentarium with previously unrecognized potential to control disease. Admittedly, future studies measuring outcomes in patients undergoing PEP are sorely needed before PEP becomes a standard of care.

This study is limited by its retrospective design and descriptive nature, and the absence of clinical information such as response rates, disease status, which might allow correlation with response at this time. Another limitation of the current study pertains to the absent inclusion of a variety of molecular markers that appear to play a significant role in driving malignant behavior or in producing drug resistance. These include P53 and PIK3CA mutation, cMET, NOTCH, and FOXM1. To the extent that pathways that cause chemotherapeutic resistance were not assayed, the report of optimal protein expression for a given patient could overestimate the chance for benefit from the associated agent.

\section{Conclusion}

We observed that a majority of patients with serous histology demonstrated protein expression associated with resistance to one or more chemotherapeutic agents. Furthermore, the resistance pattern in each individual cancer was unpredictable. Future studies could include clinical benefit analysis of MP in ovarian cancer patients in prospective trials or analysis of MA gene expression in ovarian tumors. Given the high proportion of advanced stage at diagnosis and the proclivity of ovarian cancer recurrence, efforts such as MP have the potential to make a large impact on survival of this disease.

\section{Additional file}

\section{Additional file 1: Pairing of Protein Expression Profile (PEP) with Agents.}

\section{Competing interests}

The authors disclose that they have no financial relationships and/or competing interests.

\section{Authors' contributions}

CF drafted manuscript, HD assisted id data acquisition and manuscript drafting, BM reviewed manuscript, manuscript concept, DC data acquisition manuscript review, JF manuscript concept, manuscript draft and editing. All authors read and approved the final manuscript.

\section{Acknowledgement}

The authors wish to recognize Caris Life Sciences ${ }^{\circledast}$ staff Nancy Doll, RN, CTR and Diane Stapleton, CTR, for data extraction and quality control as well as Sheri Sanders, RN, BSN, MBA for administrative and operational oversight. The authors also wish to thank Daniele A. Sumner, BA, and Angela Barber for their assistance in editing this manuscript. The authors are solely responsible for the content of this manuscript.

\section{Author details}

1 Division of Gynecologic Oncology, Department of Obstetrics and Gynecology, University of Arizona Cancer Center, 500 W. Thomas Road, Suite 600, Phoenix, AZ 85013, USA. ${ }^{2}$ Creighton University School of Medicine at Dignity Health St. Joseph's Hospital and Medical Center, 500 W. Thomas Road, Suite 600, Phoenix, AZ 85013, USA. ³ Department of Gynecologic Oncology and Reproductive Medicine, The University of Texas MD Anderson Cancer Center, Houston, TX, USA.

Received: 20 February 2014 Accepted: 15 April 2014

Published: 30 September 2014

\section{References}

1. Siegel R, Naishadham D, Jemal A: Cancer Statistics 2013. CA Cancer J Clin 2013, 63:11-30.

2. Hennessy BT, Coleman RL, Markman M: Ovarian Cancer. Lancet 2009, 374:1371-1382.

3. The Cancer Genome Atlas Research Network: Integrated genomic analyses of ovarian carcinoma. Nature 2011, 474:609-614.

4. Von Hoff DD, Stephenson JJ, Rosen P, Loesch DM, Borad MJ, Anthony S, Jameson G, Brown S, Cantafio N, Richards DA, Fitch TR, Wasserman E, Fernandez C, Green S, Sutherland W, Bittner M, Alarcon A, Mallery D, Penny R: Pilot study using molecular profiling of patient's tumors to find potential targets and select treatments for their refractory cancers. J Clin Onc 2010, 28:4877-4883.

5. Ouellet V, Guyot MC, Le Page C, Filali-Mouhim A, Lussier C, Tonin PN, Provencher DM, Mes-Masson AM: Tissue array analysis of expression microarray candidates identifies markers associated with tumor grade and outcome in serous epithelial ovarian cancer. Int J Cancer 2006, 119:599-607.

6. Jia P, Wu X, Li F, Xu Q, Wu M, Chen G, Liao G, Wang S, Zhou J, Lu Y, MA D: Breast cancer resistance protein-mediated topotecan resistance in ovarian cancer cells. Int J Gynecol Cancer 2005, 15:1042-1048.

7. Maliepaard M, van Gastelen MA, de Jong LA, Pluim D, van Waardenburg RC, Ruevekamp-Helmers MC, Floot BG, Schellens JH: Overexpression of the $\mathrm{BCRP} / \mathrm{MXR} / \mathrm{ABCP}$ gene in a topotecan-selected ovarian tumor cell line. Cancer Res 1999, 59:4559-4563.

8. Mao Q, Unadkat JD: Role of the breast cancer resistance protein (ABCG2) in drug transport. AAPS J 2005, 7:E118-E133.

9. Yuan J, Lv H, Peng B, Wang C, Yu Y, He Z: Role of BCRP as a biomarker for predicting resistance to 5 -fluorouracil in breast cancer. Cancer Chemother Pharmacol 2009, 63:1103-1110. 
10. Hogdall EV, Christensen L, Hogdall CK, Blaakaer J, Gayther S, Jacobs IJ, Christensen IJ, Kjaer SK: Prognostic value of estrogen receptor and progesterone receptor tumor expression in Danish ovarian cancer patients: from the 'MALOVA' Ovarian Cancer Study. Oncol Rep 2007, 18:1051-1059.

11. Pan Y, Kao MS: Endometrioid ovarian carcinoma benefits from aromatase inhibitors: case report and literature review. Current Oncol 2010, 17:82-85.

12. Bowman A, Gabra H, Langdon SP, Lessells A, Stewart M, Young A, Smyth JF: CA125 response is associated with estrogen receptor expression in a phase II trial of letrozole in ovarian cancer: identification of an endocrine-sensitive subgroup. Clin Cancer Res 2002, 8:2233-2239.

13. del Carmen MG, Fuller AF, Matulonis U, Horick NK, Goodman A, Duska LR Penson R, Campos S, Roche M, Seiden MV: Phase II trial of anastrozole in women with asymptomatic Mullerian cancer. Gynecol Oncol 2003, 91:596-602.

14. Papadimitriou CA, Markaki S, Siapkaras J, Viachos G, Efstathiou E, Grimani I, Hamilos G, Zorzou M, Dimopoulos MA: Hormonal therapy with letrozole for relapsed epithelial ovarian cancer. Long-term results of a phase II study. Oncology 2004, 66:112-117.

15. Smyth JF, Gourley C, Walker G, Mackean MJ, Stevenson A, Williams AR, Nafussi AA, Rye T, Rye R, Stewart M, McCurdy J, Mano M, Reed N, McMahon T, Vasey P, Gabra H, Landon SP: Antiestrogen therapy is active in selected ovarian cancer cases: the use of letrozole in estrogen-receptor positive patients. Clin Cancer Res 2007, 13:3617-3622.

16. Kaina B, Christmann M, Naumann S, Roos WP: MGMT: key node in the battle against genotoxicity, carcinogenicity and apoptosis induced by alkylating agents. DNA Repair (Amst) 2007, 6:1079-1099.

17. Casorelli I, Russo MT, Bignami M: Role of mismatch repair and MGMT in response to anticancer therapies. Anticancer Agents Med Chem 2008, 8:368-380.

18. Gerson SL: Clinical relevance of MGMT in the treatment of cancer. J Clin Oncol 2002, 20:2388-2399.

19. McCormack Al, McDonald KL, Gill AJ, Clark SJ, Burt MG, Campbell KA, Braund WJ, Little NS, Cook RJ, Grossman AB, Robinson BG, Clifton-Bligh RJ: Low 0-6-methylgaunine-DNA methyltransferase (MGMT) expression and response to temozolomide in aggressive pituitary tumours. Clin Endocrinol (Oxf) 2009, 71:226-233.

20. Davidson JD, Ma L, Flagella M, Geeganage S, Gelbert LM, Slapak CA: An increase in the expression of ribonucleotide reductase large subunit 1 is associated with gemcitabine resistance in non-small cell lung cancer cell lines. Cancer Res 2004, 64:3761-3766.

21. Zhao LP, Xue C, Zhang JW, Hu ZH, Zhao YY, Zhang J, Huang Y, Zhao HY, Zhang L: Expression of RRM1 and its correlation with sensitivity to gemcitabine-based chemotherapy in advanced nasorpharyngeal carcinoma. Chin J Cancer 2012, 31:476-483.

22. Bergman AM, Eijk PP, van Haperen WW R, Smid K, Veerman G, Hubeek I, van den ljssel P, Ylstra B, Peters GJ: In vivo induction of resistance to gemcitabine results in increased expression of ribonucleotide reductase subunit M1 as the major determinant. Cancer Res 2005, 65:9510-9516.

23. Bepler G, Kusmartseva I, Sharma S, Gautam A, Cantor A, Sharma A, Simon G: RRM1 modulated in vitro and in vivo efficacy of gemcitabine and platinum in non-small-cell lung cancer. J Clin Oncol 2006, 24:4731-4737.

24. Nakahira S, Nakamori S, Tsujie M, Takahashi Y, Okami J, Yoshioka S, Yamasaki M, Marubashi S, Takemasa I, Miyamoto A, Takeda Y, Nagano H, Dono K, Umeshita K, Sakon M, Monden M: Involvement of ribonucleotide reductase $\mathrm{M} 1$ subunit overexpression in gemcitabine resistance of human pancreatic cancer. Int I Cancer 2007, 120:1355-1363.

25. Rosell R, Danenberg KD, Alberola V, Bepler G, Sanchez JJ, Camps C, Provencio M, Isla D, Taron M, Diz P, Artal A, Spanish Lung Cancer Group: Ribonucleotide reductase mRNA expression and survival in gemcitabine/ cisplatin-treated advanced non-small-cell lung cancer patients. Clin Cancer Res 2004, 10:1318-1325.

doi:10.1186/2053-6844-1-4

Cite this article as: Foss et al.: Protein profiling of ovarian cancers by immunohistochemistry to identify potential target pathways. Gynecologic Oncology Research and Practice 2014 1:4

\section{Submit your next manuscript to BioMed Central and take full advantage of:}

- Convenient online submission

- Thorough peer review

- No space constraints or color figure charges

- Immediate publication on acceptance

- Inclusion in PubMed, CAS, Scopus and Google Scholar

- Research which is freely available for redistribution

Submit your manuscript at www.biomedcentral.com/submit
C Biomed Central 